\title{
Correlação da idade dos pais dos portadores de Síndrome de Down em instituições privadas de Campina Grande (PB)
}

\author{
The age correlation of parents of down syndrome patients in private institutions \\ of Campina Grande (PB) \\ Maria Helena Chaves de Vasconcelos Catão \\ Doutora em Laser em Odontologia/UFBA e Professora do Programa \\ em Pós-Graduação em Odontologia da Universidade Estadual da Paraíba. \\ Sérgio Neto da Silva Rocha \\ Cirurgião-dentista Graduado pela Universidade Estadual da Paraíba. \\ Roniery de Oliveira Costa \\ Mestre em Odontologia pelo Programa em Pós-Graduação \\ da Universidade Estadual da Paraíba.
}

\begin{abstract}
RESUMO
Objetivo: Este estudo avaliou a idade, o perfil socioeconômico e a profissão dos pais dos portadores de síndrome de Down matriculados na Associação de Pais e Amigos de Pacientes Especiais (Apae) de Campina Grande (PB). Material e Métodos: O instrumento utilizado para a coleta dos dados foi a ficha clínica individual do aluno, que continha todas as informações pessoais e nome dos pais ou responsáveis. A amostra foi de oitenta alunos, de ambos os sexos e na faixa etária de 2 a 32 anos. Resultados: Quanto à idade paterna, percebeu-se que o maior percentual correspondeu à faixa etária de 31 a 36 anos, enquanto na idade materna o maior percentual foi na faixa etária acima de 33 anos. Conclusão: Portanto, concluiuse que a idade materna avançada para procriação pode aumentar a incidência de progênie com síndrome de Down.
\end{abstract}

Palavras-chaves: SíndRome de Down, Trissomia, IDADE MATERnA.

\section{ABSTRACT}

Objective: This study evaluated the age, the socio-economic profile, and the occupation of parents of Down syndrome patients enrolled in the Association of Parents and Friends of Special Needs Patients (APAE) in Campina Grande, PB. Material and Methods: The instrument used for data collection was the student's individual clinical file, which contained all the personal information and names of parents or guardians. The sample was constituted by 80 students of both sexes and with ages between 2 and 32 years. Results: As to the fathers' age it was observed that most of them were aged between 31-36 years, and mothers' ages showed that the highest percentage was above 33 years. Conclusion: Therefore, it was concluded that advanced maternal age may increase the incidence of children with Down syndrome.

Keywords: Down SYNDROME, Trisomy, MATERnAl Age. 


\section{INTRODUÇÃO}

A síndrome de Down é uma anomalia congênita causada pela presença de um cromossomo a mais no par 21.1,2 Nessa anomalia podem ser também observadas outras formas de trissomia que podem ocorrer em mosaicismo, com células normais e outras com trissomia 21 , em $1 \%$ a $2 \%$ dos portadores da síndrome, além de translocações, geralmente entre os cromossomos 14 e 21, em cerca de $3 \%$ a $4 \%$ dos casos. $^{3} \mathrm{Na}$ maioria dos estudos, o distúrbio cromossômico devese à nova mutação, sem chances maiores de recorrência na família. ${ }^{4}$

Essa síndrome comumente acarreta complicações clínicas que acabam por interferir no desenvolvimento global da criança portadora, sendo frequentemente encontradas alterações cardíacas, hipotonia, complicações respiratórias, alterações sensoriais e no sistema estomatognático. ${ }^{5}$

A frequência da síndrome de Down registrada na América do Sul é de um caso em cerca de 700 nascimentos (1,4/1000), e a possibilidade de sua ocorrência aumenta com a idade materna: aos 20 anos é de 0,07\%, passando para $0,3 \%$ aos $35,1 \%$ aos 40 e quase $3 \%$ após os 45 anos. ${ }^{6}$ Como explicação para esse fenômeno tem sido considerado que a formação dos óvulos, iniciada no período fetal, e o tempo necessário para completar o processo deixariam as células germinativas femininas (ovócitos) expostas a danos ambientais que poderiam levar a erros durante a divisão meiótica. ${ }^{4}$

A idade materna após 35 anos é um dos principais fatores contribuintes para a ocorrência da trissomia do 21. Pesquisas mostram que a idade paterna avançada também pode ser um fator contribuinte. ${ }^{7-10}$

Pesquisas relacionam essa síndrome à idade materna. Mães com idade avançada apresentam um risco elevado de ter filhos com síndrome de Down. ${ }^{8-10}$ Por isso, a análise cromossômica fetal (por amniocentese ou punção de vilosidades coriônicas) atualmente é recomendada para estes casos. ${ }^{11} \mathrm{~A}$ ovulogênese completa pode levar até quarenta anos, uma vez que é iniciada na fase embrionária, interrompida antes do nascimento, e completada somente no período de cada ovulação. ${ }^{12}$

Deste modo, o "envelhecimento" dos ovócitos poderia provocar a destruição das fibras cromossômicas ou a deterioração do centrômero; isso sugere que a incapacidade de separação desses cromossomos em decorrência da idade ocorre somente durante a anáfase I da meiose, e não na II. ${ }^{13}$

Portanto, conforme a questão levantada na revisão de literatura, o objetivo deste estudo foi avaliar a idade dos pais dos portadores de síndrome de Down institucionalizados na Associação de Pais e Amigos de Pacientes Especiais (Apae) de Campina Grande (PB).

\section{Métodos}

Neste estudo foi utilizada uma abordagem indutiva com procedimento descritivo, sendo a técnica de pesquisa documental direta por meio de pesquisa de campo, tendo como instrumento para coleta de dados uma ficha clínica contendo todas as informações dos portadores de síndrome de Down matriculados na Apae de Campina Grande (PB). A amostra desse estudo compreendeu todos os portadores de síndrome de Down devidamente matriculados na Apae de Campina Grande, de ambos os sexos, e em todas as faixas etárias. Para critério de inclusão, foram considerados alunos com síndrome de Down devidamente enquadrados nos objetivos almejados pela presente pesquisa, com o total de oitenta participantes. De acordo com o critério de exclusão desse estudo, foram descartados trinta prontuários que possuíam dados incompletos. Aamostra final continha cinquenta prontuários corretamente preenchidos com as 
seguintes informações: data de nascimento e procedência do aluno, idade, condição socioeconômica e a profissão dos pais.

Esta pesquisa, atendendo à Resolução 196/96 do Ministério da Saúde, foi encaminhada e aprovada pelo Comitê de Ética, sob número CAAE 0984.0.133.0005-05.

Foi realizada a análise descritiva dos dados por meio de tabelas de frequência com número e percentual para cada um dos itens do instrumento de pesquisa.

\section{Resultados}

Observa-se que $52,5 \%$ dos alunos matriculados na Apae de Campina Grande são do sexo masculino, sendo que a distribuição da idade paterna na época do nascimento do filho teve como amostra um total de cinquenta participantes; verifica-se que $18,37 \%$ estavam na faixa etária entre 19 e 24 anos; entretanto, o maior percentual foi na faixa etária acima de 31 anos, com 65,31\% (Gráfico 1).

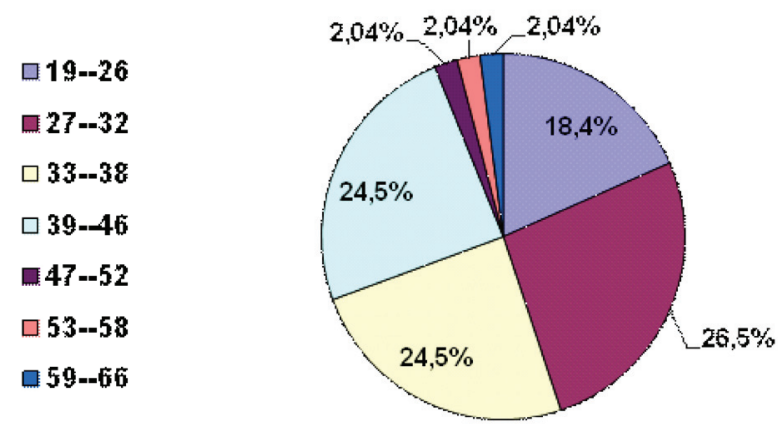

Gráfico 1 - Distribuição percentual da idade paterna no ano do nascimento do crianças com síndrome de Down matriculadas na Apae de Campina Grande

O Gráfico 2 mostra a distribuição percentual da idade materna no ano do nascimento do filho com síndrome de Down matriculado na Apae de Campina Grande. Verifica-se que na faixa etária de 15 a 20 anos foi 18,64\%; no entanto o maior percentual foi observado na faixa etária acima dos 33 anos, com 52,54\%.
O Gráfico 3 apresenta a distribuição dos alunos com essa síndrome matriculados na Apae de Campina Grande em intervalos de classe de idade, nas quais se observa o maior percentual da amostra na faixa etária entre 0 e 10 anos, com 66 (51,5\%) alunos com síndrome de Down.

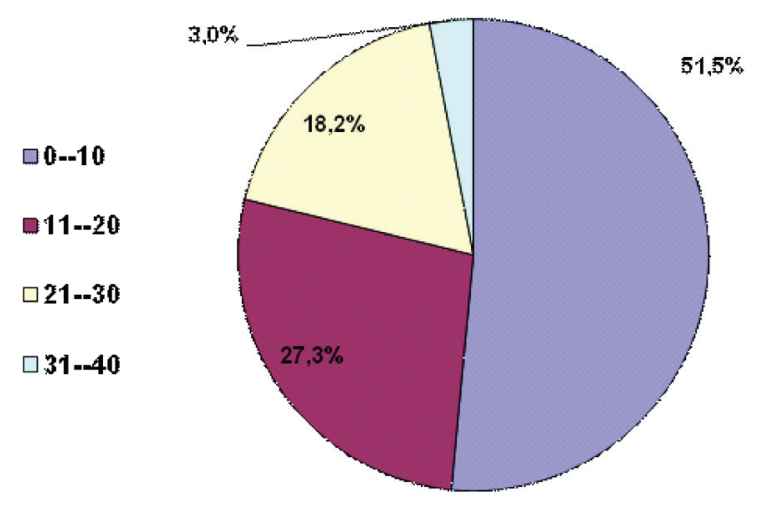

Gráfico 2 - Distribuição percentual da idade materna dos alunos matriculados na Apae de Campina Grande no ano do nascimento do portador de Síndrome de Down

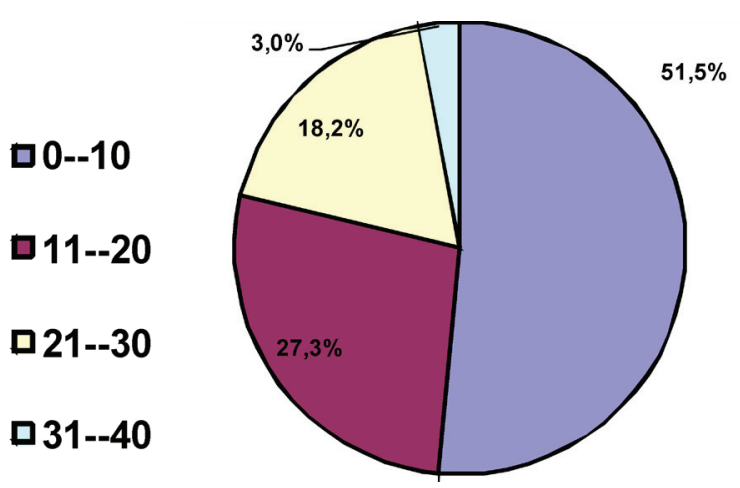

Gráfico 3 - Distribuição percentual da idade dos alunos portadores de síndrome de Down, matriculados na Apae de Campina Grande/PB.

\section{Dıscussão}

O diagnóstico pré-natal é geralmente realizado para mães maiores de 35 anos, uma vez que os dados sobre a incidência das anormalidades citogenéticas fetais é influenciada pela idade materna avançada, que aumenta o risco de trissomia. ${ }^{10,14} \mathrm{O}$ presente estudo sugere que é real a influência da idade mais avançada 
dos pais para a ocorrência de um maior número de nascidos portadores de Síndrome de Down na região de Campina Grande.

Diante disso, vale salientar que pesquisadores consideram a idade materna mais avançada a maior causa do nascimento de portadores de síndrome de Down. A idade reprodutiva está claramente relacionada à origem de trissomias cromossômicas em humanos e a idade materna acima de 35 anos é uma variável fortemente associada à síndrome de Down, sendo a frequência estimada em cerca de 1 a cada 600 nascimentos vivos e a cada 150 concepções. ${ }^{15}$

Comparando-se os resultados relativos à idade materna no período do nascimento do filho portador de síndrome de Down, pode-se perceber que o maior percentual está na faixa etária acima de 33 anos, o que confirma os resultados de vários autores. ${ }^{10,15,16,17}$ Outros estudos contrariam esses resultados, ${ }^{18,19}$ destacando que a idade reprodutiva está inequivocamente relacionada à origem de trissomias cromossômicas em humanos, e a idade materna avançada, comumente definida acima de 35 anos, é fortemente variável.

Os resultados obtidos nessa pesquisa confirmaram os encontrados na literatura, pois foram encontradas mães de crianças com síndrome de Down em todas as faixas etária, mas a maior incidência ocorre em mães com idades entre 30 e 39 anos.

Em relação à idade paterna na época do nascimento do filho, o maior percentual foi na faixa etária acima de 31 anos, concordando com os resultados de alguns autores ${ }^{20}$ que afirmam que outros fatores etiológicos, tais como alterações hormonais, exposição à radiação, agentes químicos e a idade paterna avançada, contribuem para o nascimento de crianças com trissomia do 21.

Hassold e Sherman ${ }^{16}$ também alegam que os efeitos da idade estão restritos aos casos de origem materna, e que casos de trissomia $21 \mathrm{de}$ origem paterna ou de origem pós-zigótica são independentes da idade. Isto ocorre em virtude de o homem ter o período de fertilidade mais prolongado do que a mulher, haja vista que o resultado encontrado na presente pesquisa é bastante variável com relação à idade paterna. Em contrapartida aos autores supracitados, ${ }^{16,20}$ esta pesquisa mostra que o maior percentual de ocorrência $(28,58 \%)$ está relacionado a pais com idades entre 31 e 36 anos. Observase que a literatura ainda é contraditória com relação à idade dos pais dos portadores de síndrome de Down, tornando oportunas mais pesquisas sobre o assunto.

\section{Conclusão}

A síndrome de Down é o distúrbio cromossômico mais comumente encontrado e estudado na literatura. Os resultados obtidos neste estudo sugerem que a idade materna avançada, acima de 33 anos, pode favorecer o aumento de filhos portadores da síndrome de Down. Entretanto, espera-se que haja mais fundamentação a respeito da influência da idade materna e paterna porque, apesar de várias pesquisas na literatura, verificouse que ainda existe muita controvérsia sobre o assunto, já que são encontradas várias ocorrências dessa síndrome em mulheres de todas as faixas etárias.

\section{REFERÊNCIAS BIBLIOGRÁFICAS}

1. Kagan KO, Wright $D$, Maiz $N$. et al. Screening for trisomy 18 by maternal age, fetal nuchal translucency free beta-human chorionic gonadotropin, and pregnancy-associated plasma protein-A. Ultrasound Obstet Gynecol, 2008; 32(4):488-92.

2. Kurabayashi N, Sanada K. Increased dosage of DYRK1A and DSCR1 delays neuronal differentiation in neocortical progenitor cells. Genes Dev, 2013; 27(24):2708-21.

3. Moreira LMA, Ferrari I. Um caso de translocação balanceada $14 q / 21 q$ de ocorrência familial. Ciênc Cult, 1977; 29:309-11. 
4. Gusmão FAF, Moreira LMA. Aspectos genéticos e sociais da sexualidade em pessoas com síndrome de Down. Rev Bras Psiquiatr, 2002; 24(2):94-9.

5. Carvalho ACA, Campos PSF, Crusoé-Rebello I. Síndrome de Down: aspectos relacionados ao sistema estomatognático. Rev Cien Méd Biol, 2010; 9(Supl.1):49-52.

6. Castilla EE, Lopez-Camelo JS, Paz JE, et al. Prevención primaria de los defectos congénitos. Rio de Janeiro: Fiocruz; 1996.

7. Zhu JL, Madsen KM, Vestergaard $M$, et al. Paternal age and congenital malformations. Human Reprod, 2005; 20(11):3173-7.

8. Vashist $Y$, Neelkamal M. Edad materna: un factor de controversia en la trisomía 21 / Maternal age: a controversial factor in trisomy 21. Rev Síndr Down, 2013; 17(1):8-12.

9. Szabó A, Alasztics B, Bánhidy $F$, Valent $S$. Screening of trisomy 21 nowadays. Is maternal age so important? Orv Hetil, 2013; 154(26):1026-30.

10. Kwon JY, Park IY, Kwon SM, Kim CJ, Shin JC. The quadruple test for Down syndrome screening in pregnant women of advanced maternal age. Arch Gynecol Obstet, 2012; 285(3):629-33.

11. Garcia LFM, Flores ERS, Sagrillo MR. Levantamento epidemiológico de indivíduos com características sindrômicas de aneuploidias: prevalência da síndrome de Down? Disciplinarum Scientia. Ciências da Saúde, 2009; 10(1):1-10.

12. Nakadonari EK, Soares AA. Síndrome de Down: considerações gerais sobre a influência da idade materna avançada. Arq Mudi, 2006; 10(2):5-9.

13. Oliver TR, Feingold E, YU K, et al. New insights into human nondisjunction of chromosome 21 in oocytes. PLoS Genet, 2008; 4(3):e1000033.

14. Capelle, X, Schaaps, JP, Foidart, JM. New methods of prenatal screening for trisomy 21. Rev Med Liege, 2008; 63(2):82-6.
15. Hernandez D, Fisher EMC. Down syndrome genetics: Unravelling a multifactorial disorder. Hum Molec Genet, 1996; 5:1411-16.

16. Hassold T, Sherman S. Down syndrome: Genetic recombination and the origin of the extra chromosome 21. Clin Genet, 2000; 57:95-100.

17. Offerdal K, Blaas HG, Eik-nes SH. Prenatal detection of trisomy 21 by second-trimester ultrasound examination and maternal age in a non-selected population of 49314 births in Norway. Ultrasound Obstet Gynecol, 2008; 32(4):493-500.

18. Gusmão FAF, Tavares EJM, Azevedo MLM. Idade materna e síndrome de Down no nordeste do Brasil. Cad Saúde Pública, 2003; 19(4):973-8.

19. Strah DM, Pohar M, Gersak K. Risk assessment of trisomy 21 by maternal age and fetal nuchal translucency thickness in 7,096 unselected pregnancies in Slovenia. J Perinat Med, 2008; 36(2):145-50.

20. Aguiar SMHCA, Barbieri CM, Castro AM. Incidência da síndrome de Down associada à idade materna mais avançada. J Bras Clin Odontol Integr, 2003; 7(38):166-8.

\section{Endereço para correspondência}

\section{Roniery de Oliveira Costa}

Universidade Estadual da Paraíba, Centro de Ciências Biológicas e da Saúde, Departamento de Odontologia. Rua Juvêncio Arruda s/n, Bodocongó, 58.100-000. Campina Grande, Paraíba,PB, Brasil. Telefone: (83) 88937049. Correspondência para: Costa RO. Email: ronieryoliveira@hotmail.com

Submetido em: 14-2-2014

Aceito em: 16-6-2014 